NIST Technical Note 2039

\title{
Measurement of the Flow Resistance of Vegetation
}

Ryan Falkenstein-Smith

Kevin McGrattan

Blaza Toman

Marco Fernandez 

NIST Technical Note 2039

\title{
Measurement of the Flow Resistance of Vegetation
}

\author{
Ryan Falkenstein-Smith \\ Kevin McGrattan \\ Marco Fernandez \\ Fire Research Division \\ Engineering Laboratory \\ Blaza Toman \\ Statistical Engineering Division \\ Information Technology Laboratory
}

This publication is available free of charge from:

https://doi.org/10.6028/NIST.TN.2039

March 2019

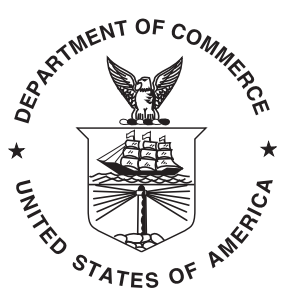

U.S. Department of Commerce Wilbur L. Ross, Jr., Secretary

National Institute of Standards and Technology Walter Copan, NIST Director and Undersecretary of Commerce for Standards and Technology 
Certain commercial entities, equipment, or materials may be identified in this document in order to describe an experimental procedure or concept adequately. Such identification is not intended to imply recommendation or endorsement by the National Institute of Standards and Technology, nor is it intended to imply that the entities, materials, or equipment are necessarily the best available for the purpose.

The opinions, recommendations, findings, and conclusions in this publication do not necessarily reflect the views or policies of NIST or the United States Government.

National Institute of Standards and Technology Technical Note 2039

Natl. Inst. Stand. Technol. Tech. Note 2039, 34 pages (March 2019) CODEN: NTNOEF

This publication is available free of charge from: https://doi.org/10.6028/NIST.TN.2039 


\begin{abstract}
This report documents the measurement of the wind resistance of different types of vegetation. The measurements are made in a wind tunnel with a $2.0 \mathrm{~m}$ test section and $0.5 \mathrm{~m}$ by $0.5 \mathrm{~m}$ cross-section. Samples of vegetation have been cut into cubical volumes that span the cross-section of the tunnel. The wind resistance is inferred via measurement of the pressure drop across the sample at wind speeds ranging from $2 \mathrm{~m} / \mathrm{s}$ to $8 \mathrm{~m} / \mathrm{s}$. The results are compared to empirical correlations quantifying the wind resistance of regularly spaced vertical tubes of comparable geometric characteristics.
\end{abstract}

\title{
Key words
}

Vegetation Canopy; Drag Coefficient; Wind Resistance 


\section{Table of Contents}

1 Introduction 1

2 Model Development 1

3 Description of Experiments 4

3.1 Sample Preparation 4

3.2 Determining the Free-Area Coefficient via Photography 4

3.3 Description of the Wind Tunnel 4

3.4 Determining the Volume of Vegetation via Water Displacement 7

4 Results $\quad 10$

4.1 Relationship between the Absorption Coefficient and Solid Fraction $\quad 10$

4.2 Vegetation Canopy Drag Coefficients 11

5 Comparison Between Vegetation Data and Tube Bank Models 17

6 Conclusion 21

References $\quad 22$

A Uncertainty Analysis of the Drag Coefficient 24

Appendix A: Uncertainty Analysis of the Drag Coefficient 24

A.1 Pressure 24

A.2 Air Density 24

A.3 Velocity 25

A.4 Free-Area Coefficient 25

B Uncertainty Analysis of the Absorption Coefficient 26

Appendix B: Uncertainty Analysis of the Absorption Coefficient 26

C Uncertainty Analysis of the Solid Fraction of Vegetation 27

Appendix C: Uncertainty Analysis of the Solid Fraction of Vegetation 27

$\begin{array}{ll}\text { C.1 Volume of Vegetation } & 27\end{array}$

C.2 Volume of Water Absorbed 27

C.3 Volume of Total Occupancy 27 


\section{List of Tables}

Table 1 Branch and leaf volume ratio of vegetation samples 10

Table 2 Drag coefficient summary of vegetation samples

Table 3 Parameters used in comparing vegetation with a comparable tube bank configuration

\section{List of Figures}

Fig. 1 Vegetation translation to multi-component model 2

Fig. 2 Cutting procedure of vegetation samples 5

Fig. 3 Prepared vegetation sample's designated orientation 6

Fig. 4 Setup for photographing vegetation samples 7

Fig. 5 Wind tunnel experimental setup 8

Fig. 6 Procedure of the water displacement test 9

Fig. 7 Comparison of absorption coefficient, $\kappa$, and solid fraction, $\beta \quad 11$

Fig. 8 Pressure drop versus velocity for all vegetative samples $\quad 12$

Fig. 9 Determination of the drag coefficient for all vegetative samples 13

Fig. 10 Distribution of vegetation sample drag coefficients 14

Fig. 11 Tube bank experimental setup 18

Fig. 12 Comparison between resistance coefficients of tube banks 19

Fig. 13 Drag coefficient comparison between vegetation samples and tube bank con$\begin{array}{ll}\text { figurations } & 20\end{array}$ 


\section{Introduction}

The Fire Research Division of the National Institute of Standards and Technology (NIST) has developed several numerical models to predict the behavior of fires within buildings. One of the models, a computational fluid dynamics (CFD) code called the Fire Dynamics Simulator (FDS) [1], has been extended to model fires in the wildland-urban interface (WUI). One crucial component of this type of modeling is the proper treatment of winddriven flow through vegetation. The objective of the experiments described in this report is to measure the drag coefficient of vegetation for an empirical sub-model appropriate for CFD.

Measurements of this type have been performed by other researchers [2-6], most of whom used wind tunnels of various sizes. In most cases, a single plant or small tree was positioned within the tunnel and the resistance force measured. However, such a measurement is not readily applicable to a CFD model which does not necessarily consider the tree as a whole but rather as a volume occupied by subgrid-scale objects that decrease the momentum of the gases flowing through. Some plants might be smaller than a characteristic grid cell, and some trees might be larger, but in either case, these objects are just momentum sinks within individual grid cells that require some drag coefficient that is appropriate to the local conditions.

\section{Model Development}

Consider a volume filled with a random collection of vegetative elements, like pine needles or leaves, as shown in Fig. 1. This volume can be regarded as a single grid cell in a CFD model for which the computational domain may span hundreds to thousands of meters. At a given instant in the numerical simulation, this grid cell would have, at the very least, an average flow speed, $U$, and gas density, $\rho$. The vegetation within the cell is typically modeled as a collection of subgrid-scale Lagrangian particles whose mass, size, and shape are characterized by a handful of parameters that can be determined with field measurements. These particles exert a force per unit volume given by:

$$
F=\frac{N}{V_{\mathrm{c}}} \frac{\rho}{2} C_{\mathrm{d}} A_{\mathrm{p}} U^{2}
$$

where $N$ is the number of elements, $V_{\mathrm{c}}$ is the volume of the grid cell, $A_{\mathrm{p}}$ is the projected area of a single element, and $C_{\mathrm{d}}$ is a drag coefficient. Similar configurations have already been been adapted in numerical investigations [7, 8]. A more convenient way to describe the vegetation is by specifying the surface to volume ratio of each element, $\sigma$, the volume (packing) ratio of the collection of elements, $\beta$, and a shape factor, $C_{\mathrm{s}}$, defined in this case as the ratio of the element's projected area to surface area. With this information, and the following relations:

$$
C_{\mathrm{s}}=\frac{A_{\mathrm{p}}}{A_{\mathrm{s}}} \quad ; \quad \beta=\frac{N V_{\mathrm{e}}}{V_{\mathrm{c}}} \quad ; \quad \sigma=\frac{A_{\mathrm{s}}}{V_{\mathrm{e}}}
$$




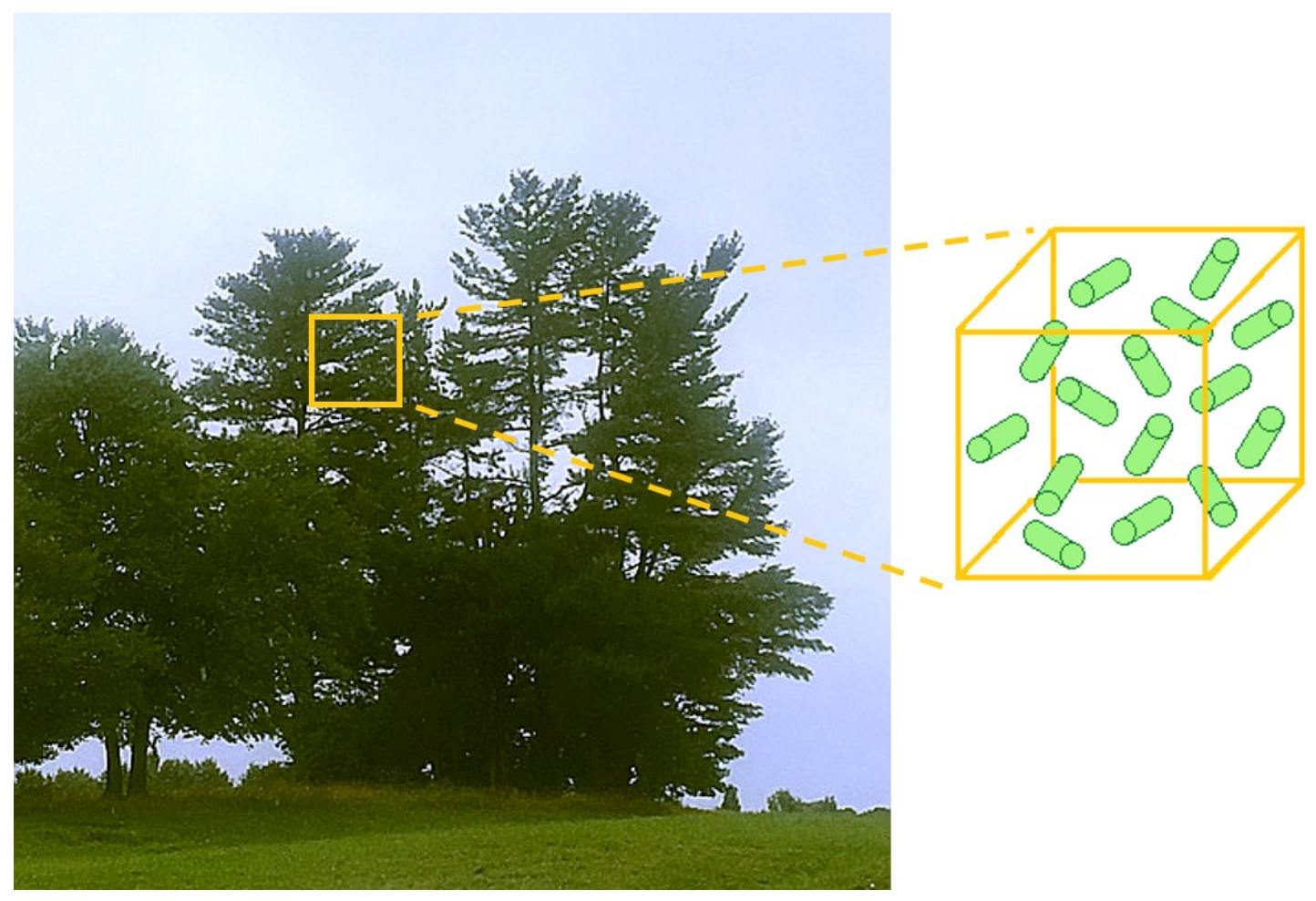

Fig. 1. Vegetation translation to multi-component model

where $V_{\mathrm{e}}$ is the volume of an element and $A_{\mathrm{s}}$ its surface area, we can convert the drag force expression in Eq. (1) to an equivalent form [9]:

$$
F=\frac{\rho}{2} C_{\mathrm{d}} C_{\mathrm{s}} \beta \sigma U^{2}
$$

Some of the terms are difficult to measure, such as the shape factor and surface to volume ratio, but collectively these terms may be combined into a single parameter:

$$
\kappa=C_{\mathrm{s}} \beta \sigma
$$

The parameter, $\kappa$, resembles an absorption coefficient ${ }^{1}$ and can be determined by measuring the projected area of light, $A$, passing a given distance $x$ through the vegetation. The decrease in the projected area of light is governed by the equation

$$
\frac{\mathrm{d} A}{\mathrm{~d} x}=-\kappa A \quad ; \quad A(x)=A(0) \mathrm{e}^{-\kappa x}
$$

The relative fraction of light passing through a distance of $L$ is

$$
W=\frac{A(L)}{A(0)}=\mathrm{e}^{-\kappa L}
$$

\footnotetext{
${ }^{1}$ Another way to express $\kappa$ using the relations in Eq. (2) is $N A_{\mathrm{p}} / V_{\mathrm{c}}$, or in other words, the total projected area per unit volume. This parameter describes the absorption of non-scattering light by solid particles using the same geometric assumption for thermal radiation absorption.
} 
The parameter $W$ is sometimes referred to as the "free-area coefficient" or "free-area fraction" in the literature.

In order to measure the drag coefficient, $C_{\mathrm{d}}$, a section of length, $L$, of a small wind tunnel is to be filled with various amounts and types of vegetation and the pressure drop, $\Delta P$, measured for an array of wind speeds, $U$. The value of $\kappa$ shall be determined via black and white photography, and the drag coefficient extracted from the following form of the drag law derived above:

$$
\frac{\Delta P}{L}=\frac{\rho}{2} C_{\mathrm{d}} \kappa U^{2}
$$




\section{Description of Experiments}

\subsection{Sample Preparation}

The vegetation chosen for this work was a Bakers Blue Spruce (Picea pungens 'Bakeri'), an Evergreen Distylium (Distylium 'PIIDIST-I'), a Gold Rider Leyland Cypress (Cupressocyparis leylandii 'Gold Rider'), a Kimberly Queen Fern (Nephrolepis obliterata 'Kimberly Queen'), a Blue Shag Eastern White Pine (Pinus strobus 'Blue Shag'), and a Robin Red Holly (Ilex opaca). Each sample was chosen based on its local availability. Leaf shapes were varied, including needle, elliptic, scale, and ovate.

The plant samples were cut into $0.5 \mathrm{~m}$ by $0.5 \mathrm{~m}$ by $0.5 \mathrm{~m}$ cubes using a guiding frame (Fig. 2). The samples completely filled the cross section of the wind tunnel forcing the flow to move through the vegetation as opposed to around it. To easily distinguish the front, back, left, and right side of the cube-shaped vegetation, each side was designated Position A, B, C, or D (Fig. 3). After its initial cut, image analysis, wind tunnel measurements, and water displacement testing were conducted in subsequent order. Image analysis and wind tunnel measurments were conducted for each position to obtain a collection of drag coefficients relative to different $\kappa$ values. In some cases, samples were pruned and tested again. In the case of the Bakers Blue Spruce, Gold Rider Leyland Cypress, and Robin Red Holly, four prunings were made with the final one being the removal of all leaves.

\subsection{Determining the Free-Area Coefficient via Photography}

The free-area coefficient, $W$, was determined by placing each vegetation sample on a table located between a large white backdrop and a $0.5 \mathrm{~m}$ by $0.5 \mathrm{~m}$ cardboard frame, the same dimensions as the tunnel cross section (Fig. 4). For each sample cut and position, the projected area was photographed. All images were captured using a Nikon D5600 camera placed on a tripod located approximately $3.6 \mathrm{~m}$ away from the sample. The white backdrop was illuminated using a collection of incandescent and LED lights.

The images were processed using MATLAB's Image Processing Toolbox. Imported colored images were first converted into a grey scale and then a binary (black and white) image using a pre-set threshold level. The binary images were then cropped within the cardboard frame to eliminate non-vegetative substances and to evaluate the projected image of the vegetation exclusively. Once the projected image was obtained, a pixel count was conducted to determine the free-area coefficient of the vegetation, $W$. Once obtained, the free-area coefficient was used to calculate $\kappa$ from Eq. (6).

The uncertainty of the free-area coefficient, $W$, and the absorption coefficient, $\kappa$, are discussed in Appendix A.4 and B, respectively .

\subsection{Description of the Wind Tunnel}

Pressure loss measurements were obtained in a wind tunnel test section with a crosssectional area of $0.5 \mathrm{~m}$ by $0.5 \mathrm{~m}$ and a length of $2 \mathrm{~m}$. An image and schematic diagram of 

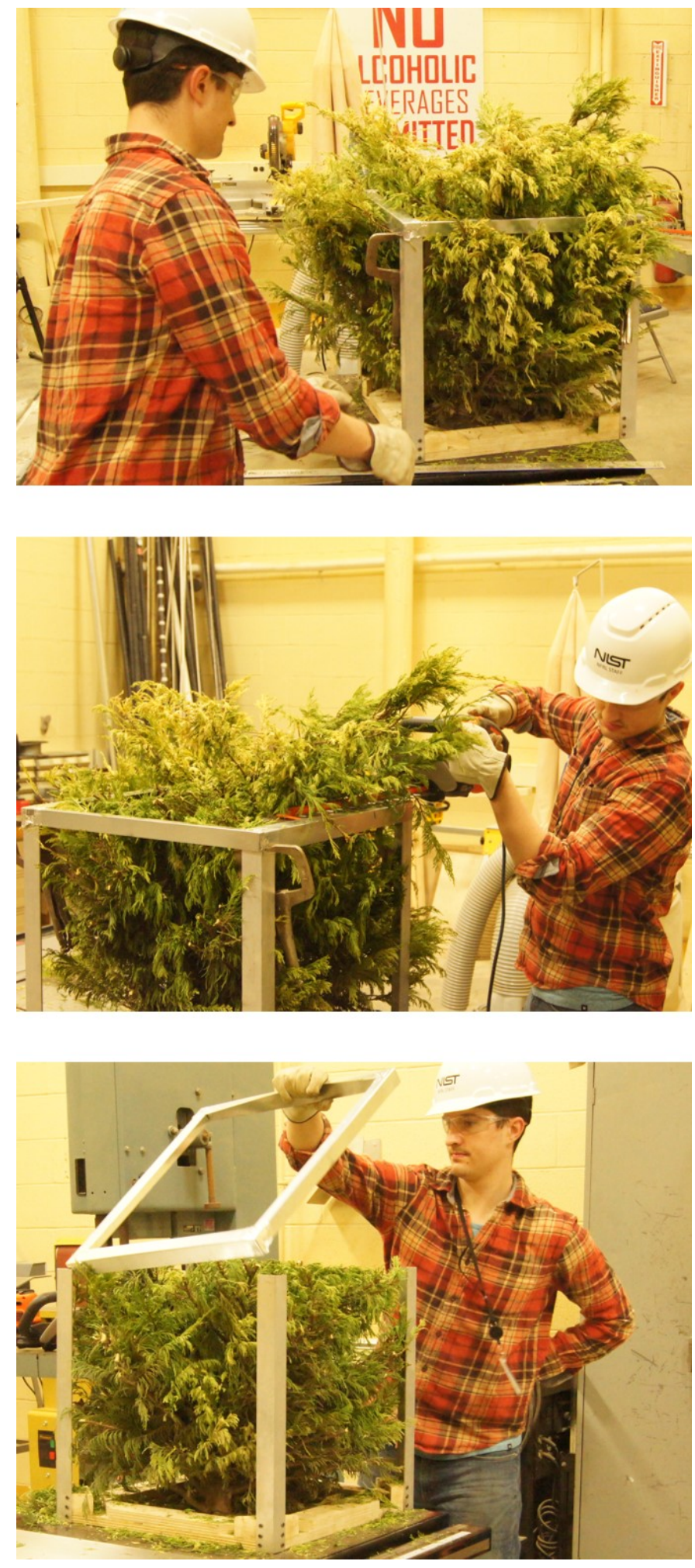

Fig. 2. Cutting procedure of vegetation samples 


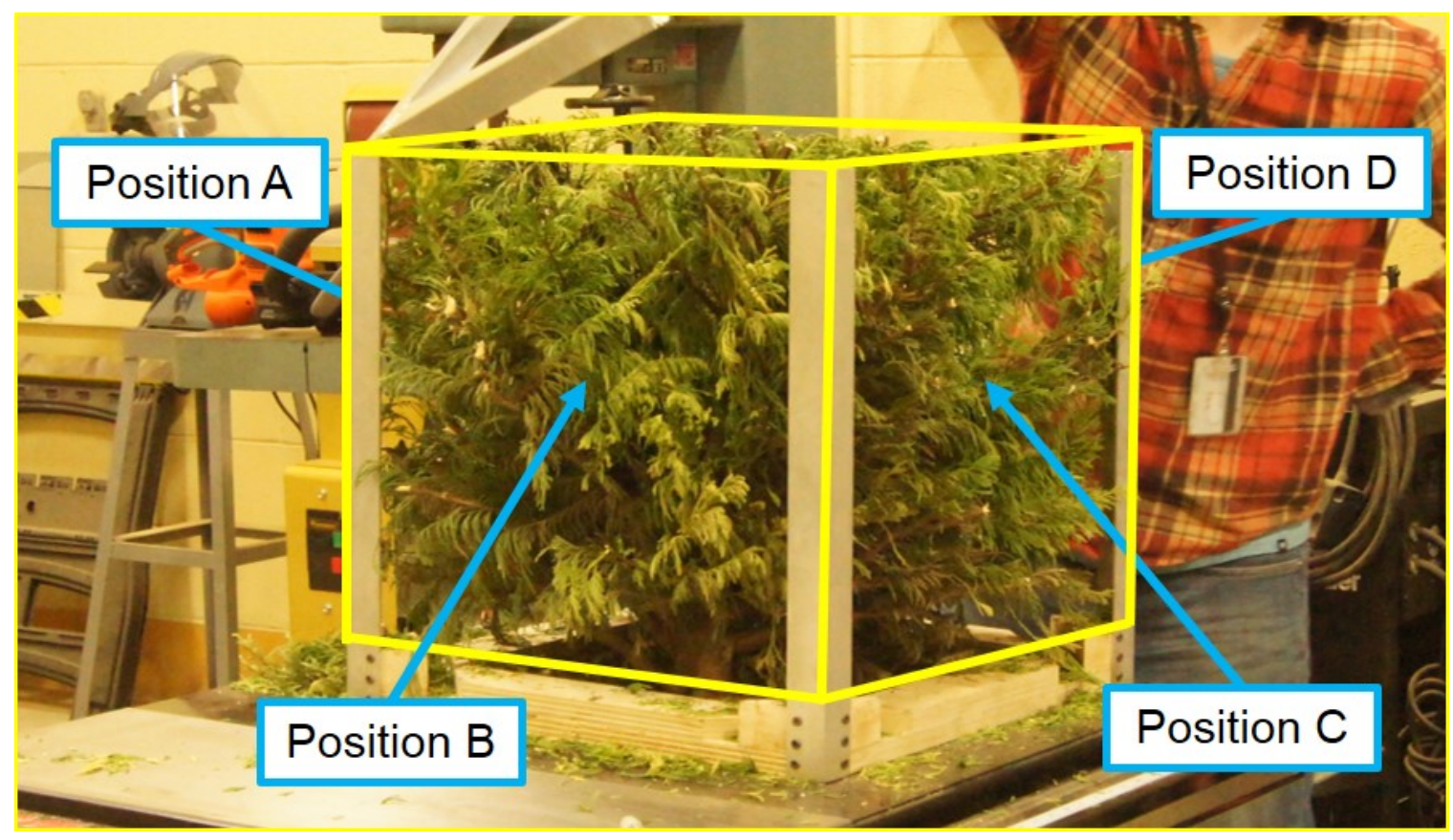

Fig. 3. Prepared vegetation sample's designated orientation

the wind tunnel setup is shown in Fig. 5. The volume flow through the tunnel was measured upstream of the vegetation using a Rosemont 485 annubar [10]. The pressure drop across the vegetation was measured using an MKS Baratron Type 220D pressure transducer with a range of 0 to $133 \mathrm{~Pa}$. The air flow was provided by a $0.91 \mathrm{~m}$ axial fan controlled by a variable frequency drive and monitored using the Annubar. Air density was calculated from pressure, temperature, and relative humidity readings of the testing facility. Each sample configuration was subjected to nine different fan speeds ranging from 0 to $88 \%$ of the full-scale fan speed. The fan speed was not run at full scale due to the risk of exceeding the pressure transducer's pressure limitations. Data was sampled at $90 \mathrm{~Hz}$ for a $30 \mathrm{~s}$ period while maintaining a constant fan speed.

Once a set of measurements was taken at all fan speeds, the wind tunnel was shut off for approximately $5 \mathrm{~min}$, and then the measurements were repeated. All measurements were repeated three times for each vegetation configuration. The variance homogeneity of the replicate measurements was tested using Hartley's $\mathrm{F}_{\max }$ test. If it was found that the data sets were homogenous, then the measurements were averaged.

An uncertainty analysis was conducted for the pressure and air density measurements and the subsequently determined velocities and drag coefficients. The characterization of the uncertainty for each parameter is provided in Appendix A. 

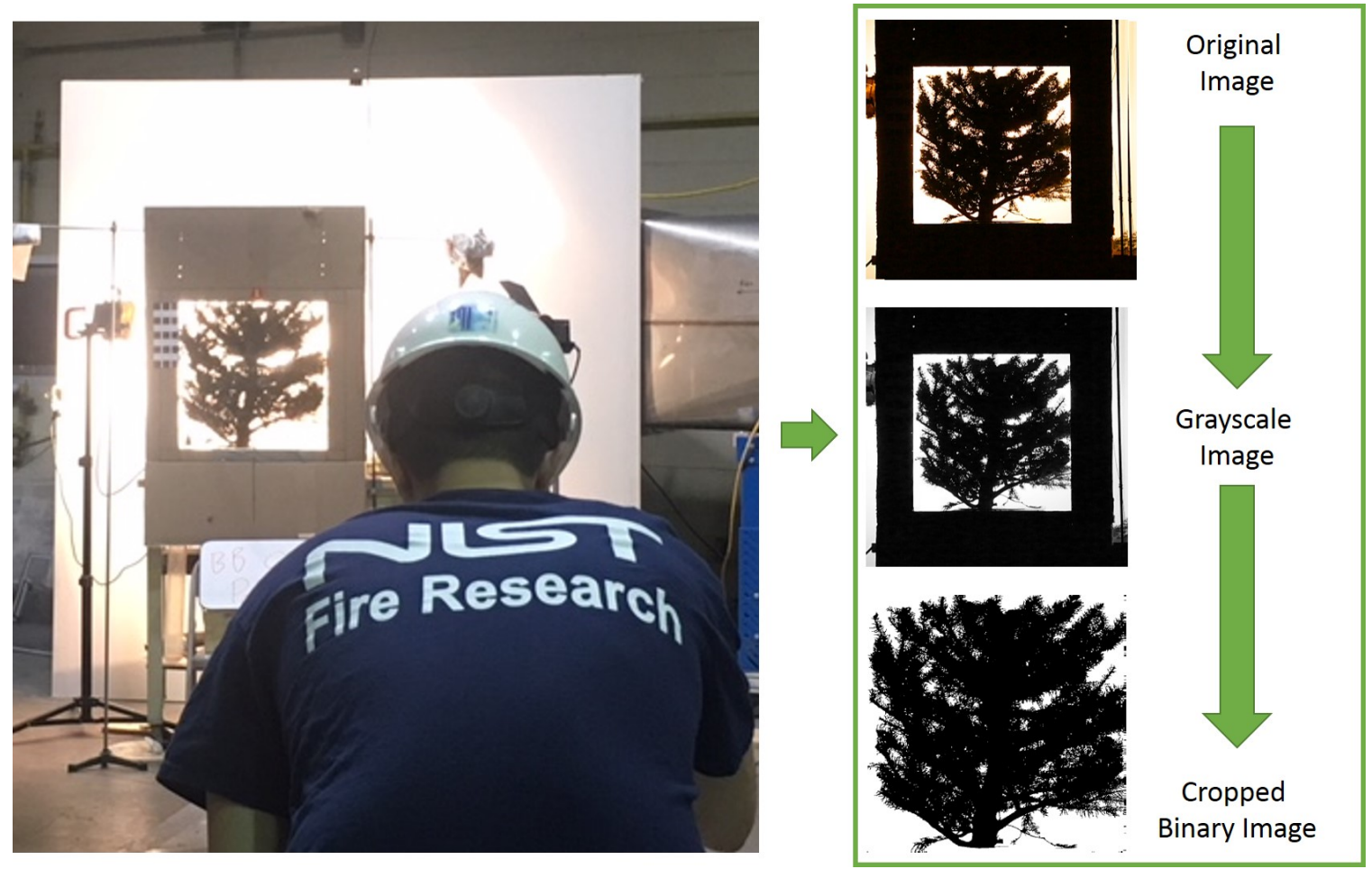

Fig. 4. Setup for photographing vegetation samples (left) and the post-processing procedure for analyzing images (right)

\subsection{Determining the Volume of Vegetation via Water Displacement}

The volume of the vegetation was measured after a sample cut. The extracted vegetation was separated into branches and leaves and put into cloth mesh bags of known mass and volume, weighed ${ }^{2}$, and submerged in a bucket. The displaced water flowed through a spout and into a beaker (Fig. 6). The measurement was repeated three times for each sample. The solid fraction, $\beta$, was calculated by dividing the average sample volume by the volume it occupied $\left(0.5 \mathrm{~m} \times 0.5 \mathrm{~m} \times 0.5 \mathrm{~m}=0.125 \mathrm{~m}^{3}\right)$.

\footnotetext{
${ }^{2}$ The mass was measured to estimate the water absorbed by the sample in between tests. The volume of water absorbed was subtracted from the volume of vegetation measured from the beaker.
} 


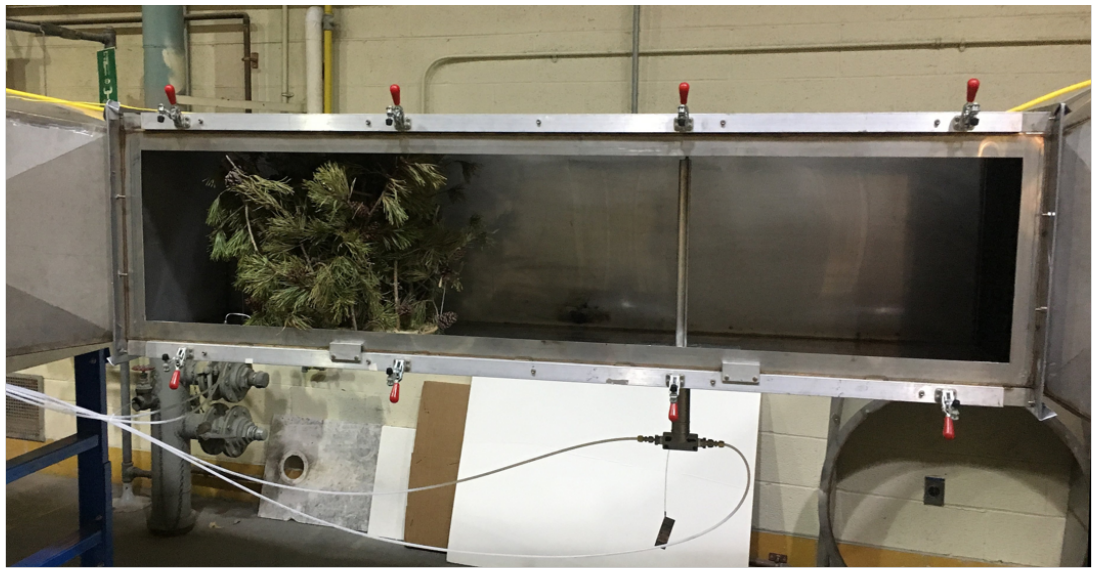

\section{$\underline{\text { Top View }}$}

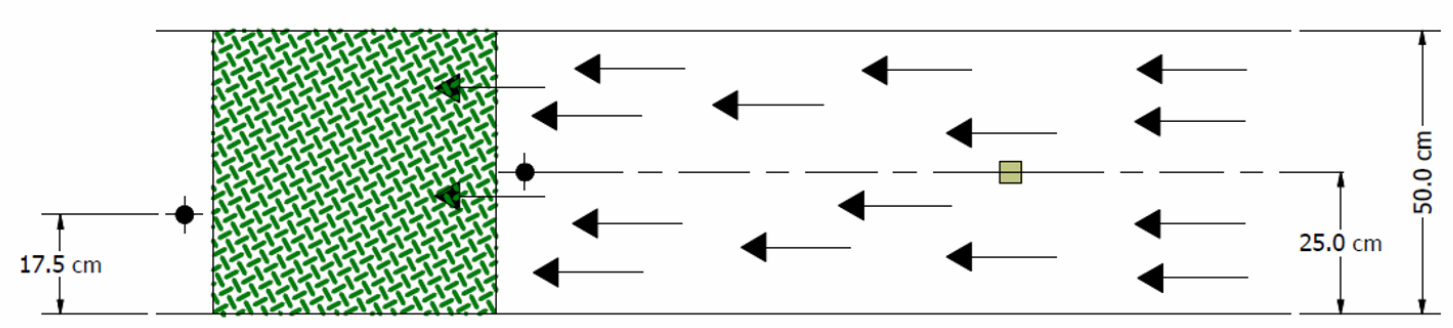

Front View

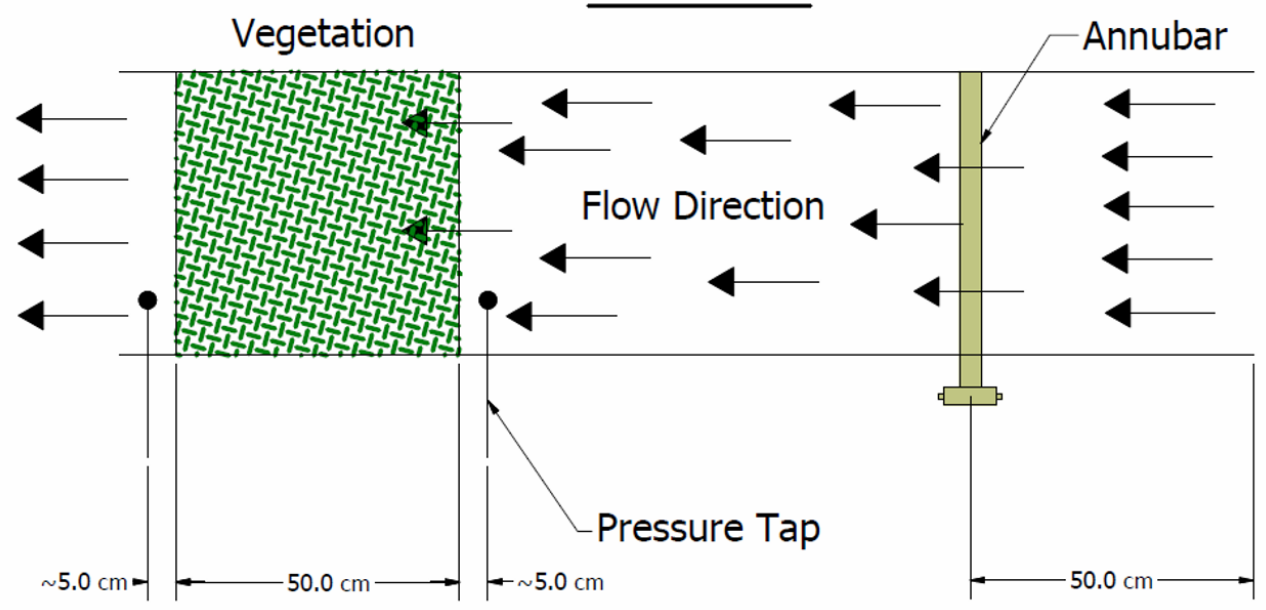

Fig. 5. Wind tunnel experimental setup with top and front schematic drawings 

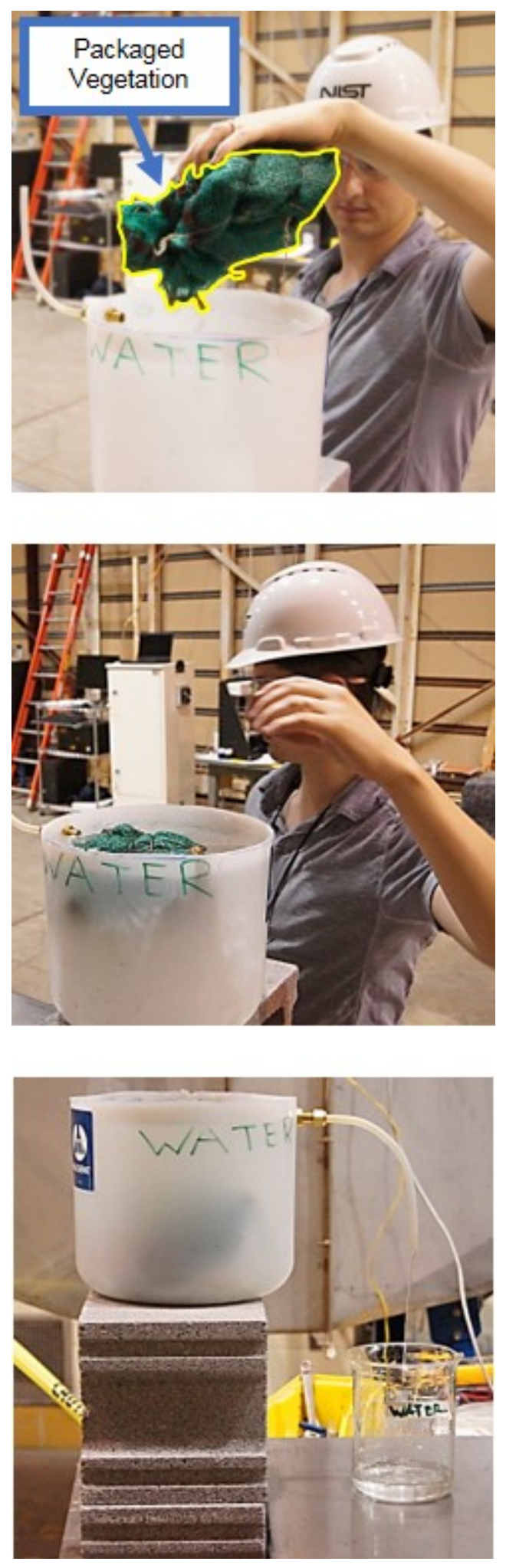

Fig. 6. Procedure of the water displacement test 


\section{Results}

The key results of this work are the relationship between the absorption coefficient, $\kappa$, and the solid fraction, $\beta$, and the drag coefficient derived from the wind tunnel measurements.

\subsection{Relationship between the Absorption Coefficient and Solid Fraction}

Figure 7 presents the relationship between the averaged absorption coefficient, $\kappa$, and the solid fraction, $\beta$, for the sample configurations of the Bakers Blue Spruce, Evergreen Distylium, Gold Rider Leyland Cypress, and Robin Red Holly. The symbols indicate the measured values while the dotted lines represent a linear regression fit. Each line represents a particular type of vegetation that has been pruned, reducing both the volume fraction, $\beta$, the projected free-area coefficient, $W$, and the corresponding value of $\kappa$. There ought to be a linear relationship between $\kappa$ and $\beta$ if the shape factor, $C_{\mathrm{s}}$, and surface to volume ratio, $\sigma$ are constant, as shown in Eq. (4). However, this is not the case when the vegetative components are not uniform in size. Take, for example, the Robin Red Holly data shown in Fig. 7. As $\beta$ decreases, $\kappa$ should approach zero, as demonstrated by most samples. As the leaves of the Robin Red Holly were pruned, $\kappa$ decreased significantly even though its volume fraction did not, owing to the fact the ratio of branch to leaf volume of the Robin Red Holly is substantially higher than the other plant species, as shown in Table 1. As a result, the free-surface area, $W$, decreases from the removal of leaves, thus reducing $\kappa$, while still maintaining a relatively consistent solid fraction due to the significant volume contribution of the branches.

Table 1. Branch and leaf volume ratio of vegetation samples with mulitple cut iterations

\begin{tabular}{lccccc}
\hline Sample & $\beta(\%)$ & Branch/Leaf Vol. & Sample & $\beta(\%)$ & Branch/Leaf Vol. \\
\hline \multirow{3}{*}{ Blue Spruce } & 1.9 & 1.1 & Cypress & 1.7 & 1.5 \\
& 1.8 & 1.3 & & 1.4 & 2.2 \\
& 1.2 & 1.5 & & 1.2 & 3.0 \\
& 0.7 & N/A & & 0.9 & N/A \\
Distylium & 0.5 & 1.0 & Red Holly & 2.7 & 11 \\
& 0.4 & 1.4 & & 2.3 & 16 \\
& 0.3 & 3.3 & & 2.2 & 47 \\
& & & & 2.1 & N/A \\
\hline
\end{tabular}




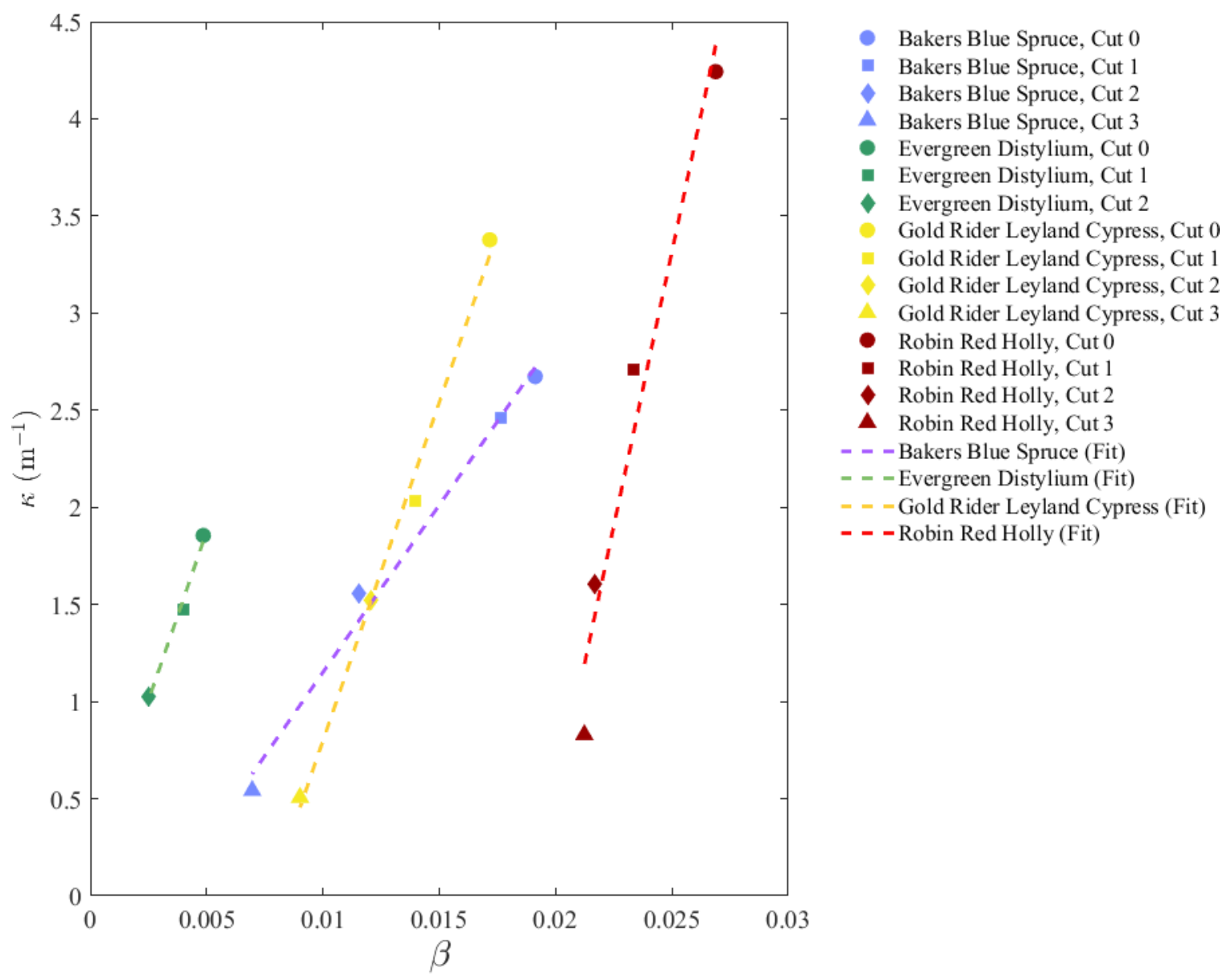

Fig. 7. Calculated absorption coefficient $(\kappa)$ of vegetation sample configuration plotted against the corresponding solid fractions $(\beta)$

\subsection{Vegetation Canopy Drag Coefficients}

Figure 8 displays the relationship between the freestream velocity and the pressure drop for each sample configuration. The results demonstrate the expected quadratic relationship. Replotting the data as shown in Fig. 9 yields the drag coefficient for each sample configuration as determined by calculating the slope of each line of data points. No linear regression fitting was observed to have a coefficient of determination less than 0.98 , indicating a close representation of the fitted regression line to the measured data. A summary of all 68 calculated drag coefficients and their respective uncertainties are presented in Table $2^{3}$.

The distribution of the measured drag coefficients for all sample configurations is shown

${ }^{3}$ The procedure for determining the drag coefficient uncertainty as shown in this table can be found in Appendix A. For most instances, the uncertainty in the velocity measurement was found to be the primary contributor to the drag coefficient uncertainty. In other cases, the uncertainty of the measured pressure loss across the vegetation was the primary contributor to the drag coefficient uncertainty. 


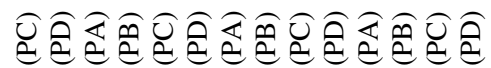

OO- -

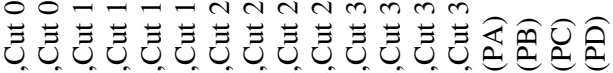

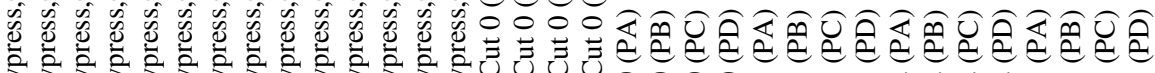
S

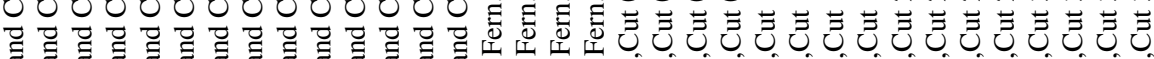

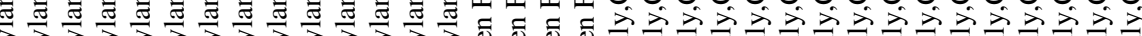

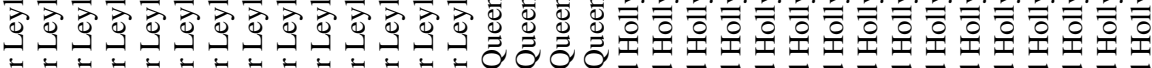

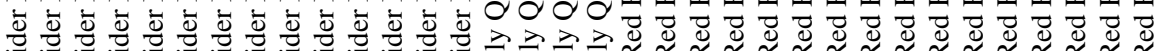

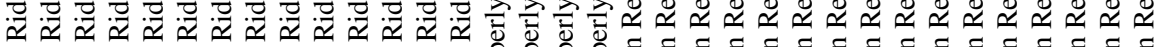

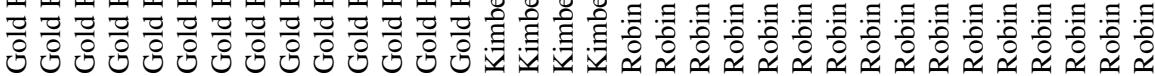

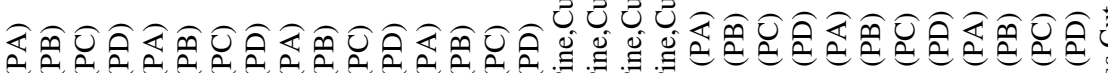

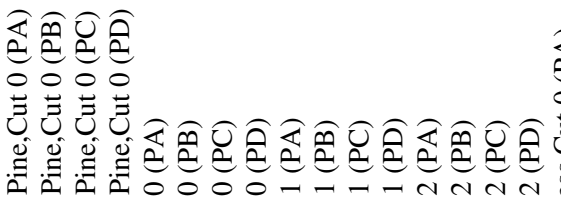
O

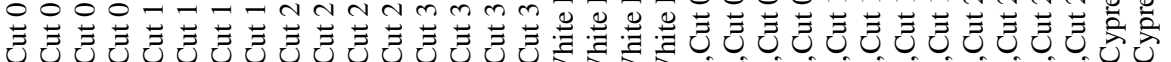

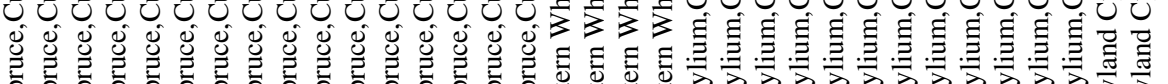

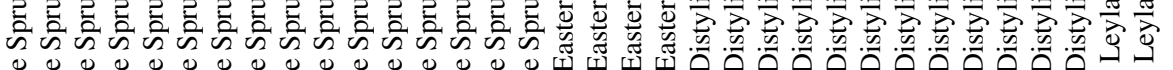

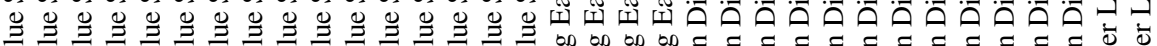

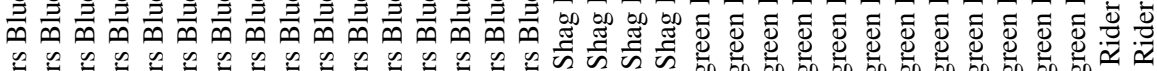

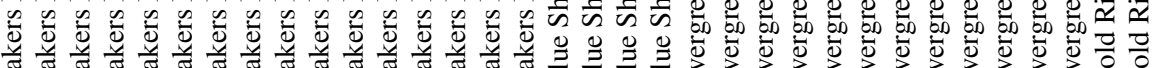

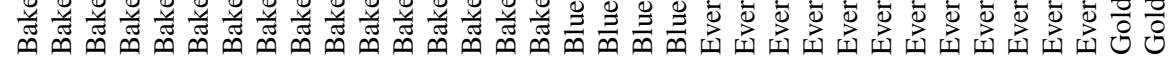

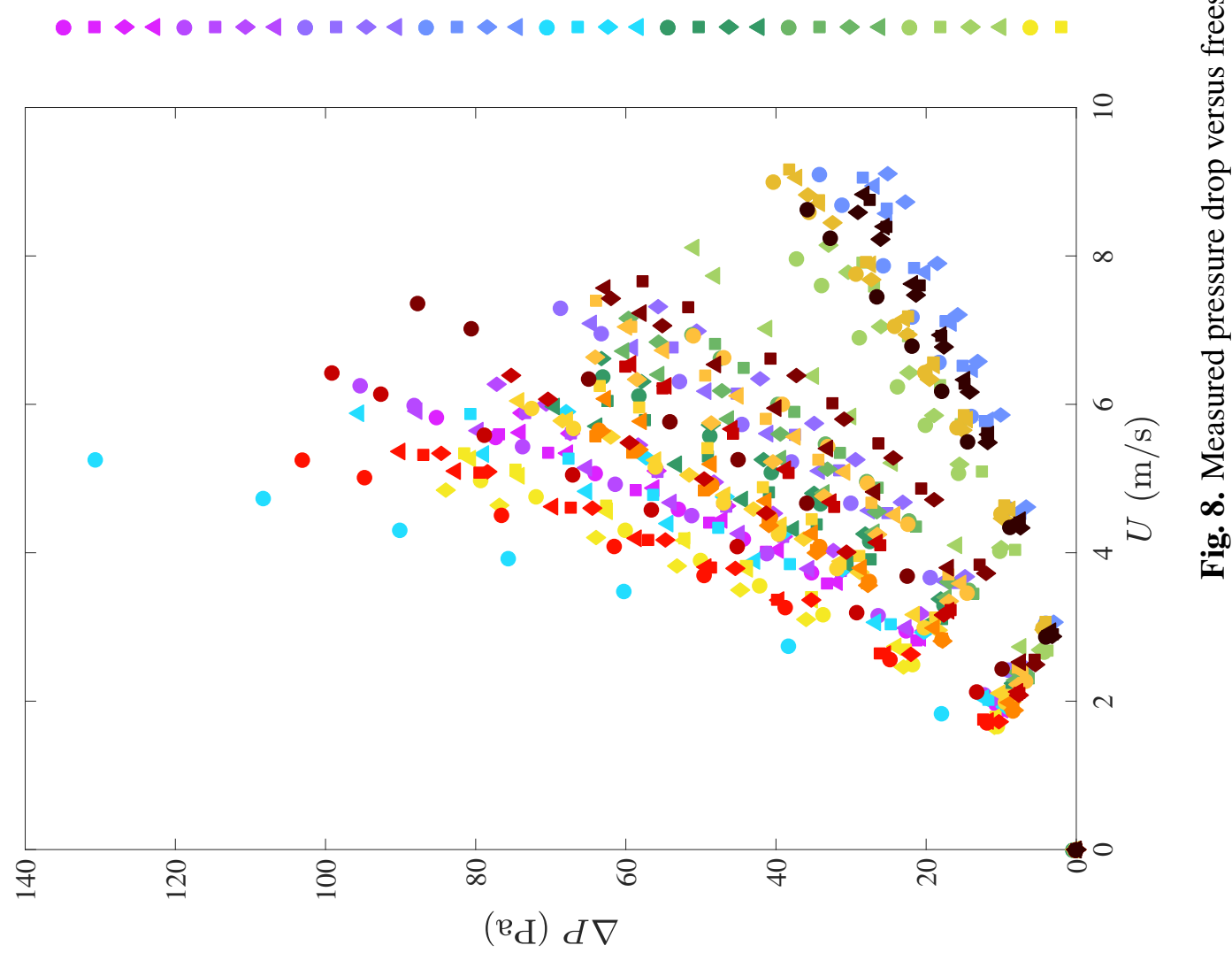




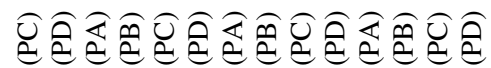

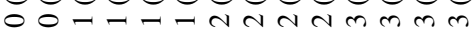

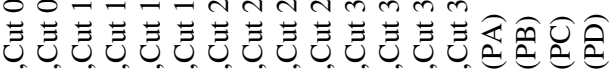

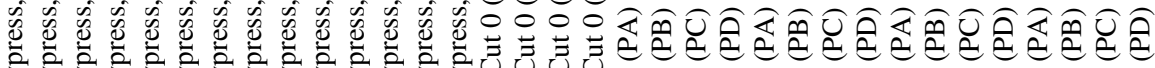
hy

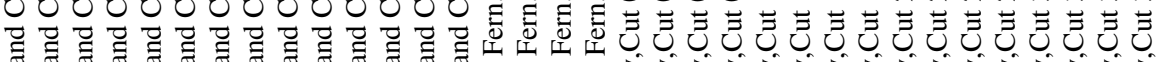

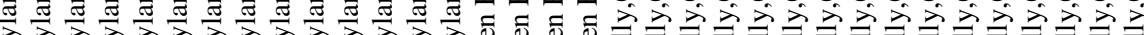

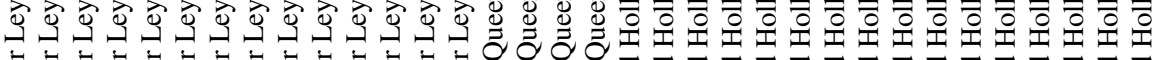

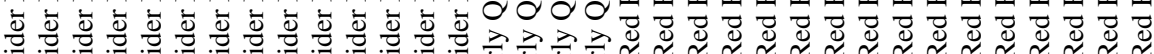

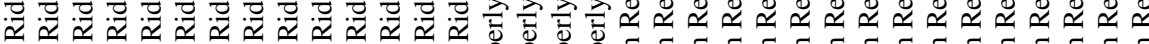

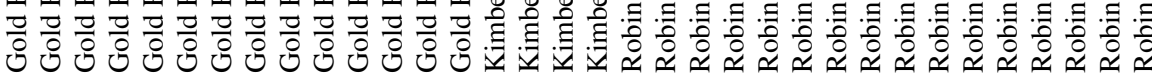

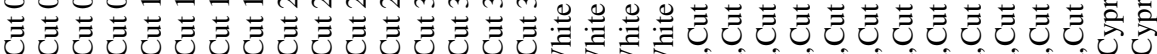
\&

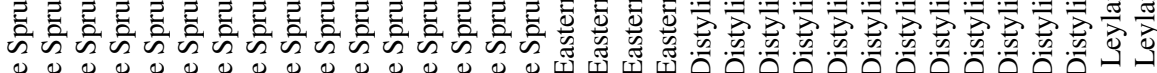

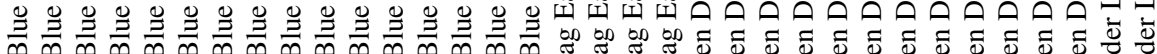

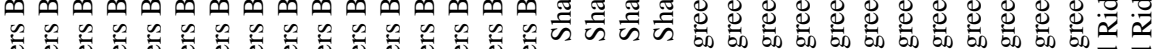

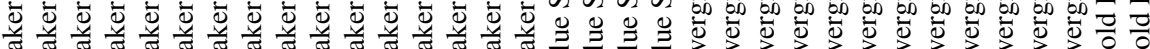

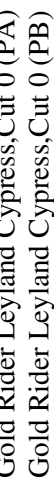

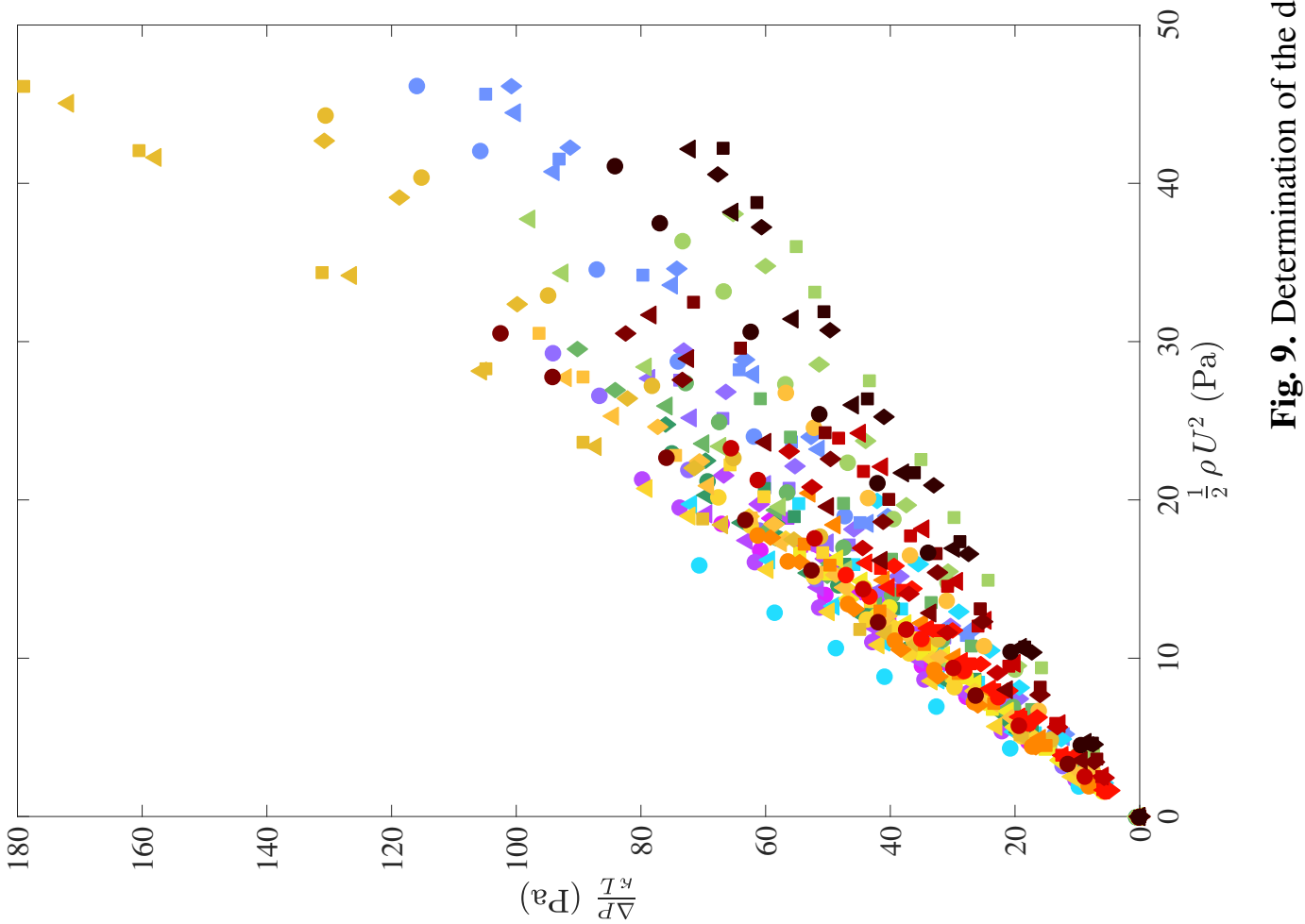



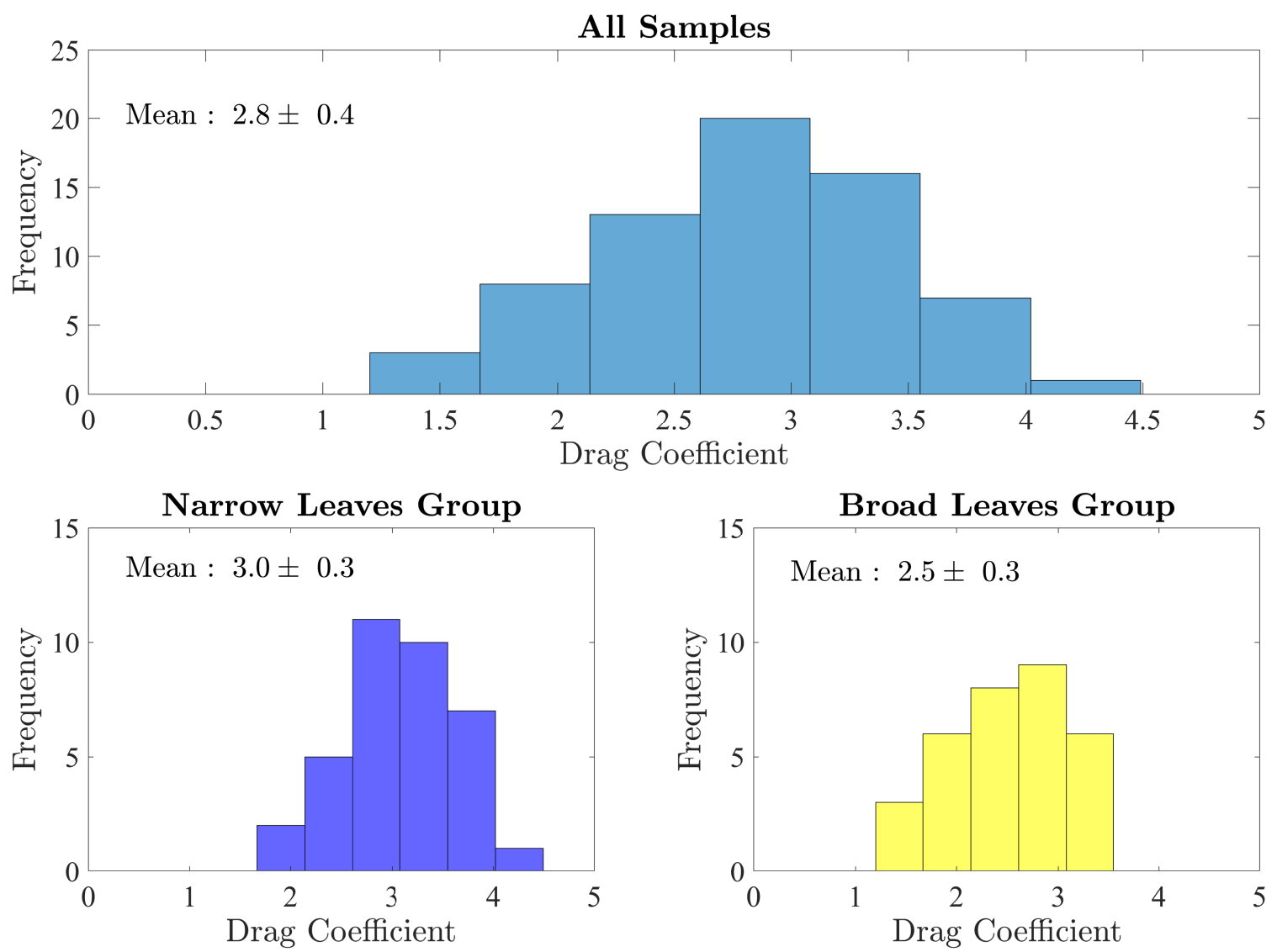

Fig. 10. Distribution of drag coefficients for all samples (top), samples with narrow leaves (bottom left), samples with broad leaves (bottom right).

in Fig. 10. The collection of sample configurations is divided into two groups based on leaf shape (i.e., narrow and broad). The narrow leaves group included the Bakers Blue Spruce, Blue Shag Eastern White Pine, and Gold Rider Leyland Cypress while the broad leaves group was comprised of the remaining species. The average drag coefficient of all sample configurations was determined to be 2.8 with an expanded uncertainty of 0.4 .

To determine if the average drag coefficient depends on the type of vegetation a random effects one-way $\mathrm{ANOVA}^{4}$ was implemented on the drag coefficients of the different vegetation samples. The analysis yielded a significant variation $(F(5,62)=4.88$, $p=7.97 \times 10^{-4}$ ) among the species ${ }^{5}$. A Tukey's test [11] was subsequently applied to determine if the species-specific average drag coefficients were significantly different from

\footnotetext{
${ }^{4}$ Analysis of Variance

${ }^{5}$ The $F$ refers to the statistic obtained from the F-test conducted in the ANOVA, the 5 and 62 in brackets represent the degrees of freedom, and the 4.88 is the actual $\mathrm{F}$ statistic derived from the ANOVA. The $p$ refers to the significance level determined from the $\mathrm{F}$ statistic and the $7.97 \times 10^{-4}$ is the actual $\mathrm{p}$-value which was determined to be less than the chosen confidence level of 0.05 , indicating a significant difference between the mean drag coefficients of the samples.
} 
each other. The results showed one significant difference between the species' average drag coefficients: the Robin Red Holly and Gold-Rider Leyland Cypress. Despite the significant difference, the average drag coefficients of these two plant species are still within the uncertainty bound of the overall drag coefficient and therefore are not large enough to have a practical implication.

Further analysis was conducted to compare the two leaf shape groups. A one-way random effects model [12] for the measurements of the narrow leaves group assumes that the drag coefficients are normally distributed:

$$
C_{\mathrm{d}, i j} \sim N\left(m_{1}, u_{i j}^{2}+\sigma_{1}^{2}\right), i=1, \ldots, 3 ; j=1, \ldots, n_{i}
$$

where $i$ denotes the plant species (1 for Bakers Blue Spruce, 2 for Blue Shag Eastern White Pine, and 3 for Gold Rider Leyland Cypress), and $j$ denotes the specific configuration of the plant in the tunnel. The sample size for a given plant species is $n_{i}$. The value of $u_{i j}$ is the standard uncertainty of the measured drag coefficient for a specific species and configuration. The parameters $m_{1}$ and $\sigma_{1}$ are the mean and standard deviation for the narrow leaves group, respectively. The drag measurements of the broad leaves group are modeled in a similar way:

$$
C_{\mathrm{d}, i j} \sim N\left(m_{2}, u_{i j}{ }^{2}+\sigma_{2}^{2}\right), i=4, \ldots, 6 ; j=1, \ldots, n_{i}
$$

where $i=4$ for Distylium, $i=5$ for Fern, and $i=6$ for Red Holly). The parameters $m_{2}$ and $\sigma_{2}$ are the mean and standard deviation for the broad leaves group, respectively.

Using a Bayesian statistical model [13] with non-informative priors for $m_{1}, m_{2}, \sigma_{1}$, and $\sigma_{2}$, we obtain via Markov Chain Monte Carlo implemented in OpenBUGS [14] the posterior means and standard uncertainties of the parameters. These are: $m_{1}$ is 3.0 with an expanded $(95 \%)$ uncertainty of $0.3, m_{2}$ is 2.5 with an expanded $(95 \%)$ uncertainty of 0.3 , and the $95 \%$ uncertainty interval for the difference $m_{1}-m_{2}$ is $(0.052,0.87)$. This may be interpreted as a rejection of a hypothesis test of $H_{0}: m_{1}-m_{2}=0$ at a level of $5 \%$. Despite the differences in the average drag coefficients of both groups, they both lie within the uncertainty bound of the overall average drag coefficient, which suggests that mean drag coefficient obtained from all samples could be a reasonable approximation when applied as a consistent drag coefficient for vegetation canopies in CFD models. 
Table 2. Drag coefficient summary of vegetation samples

\begin{tabular}{|c|c|c|c|c|c|c|c|c|c|}
\hline Sample & $\beta(\%)$ & Position & $C_{\mathrm{d}}$ & Uncertainty & Sample & $\beta(\%)$ & Position & $C_{\mathrm{d}}$ & Uncertainty \\
\hline \multirow[t]{16}{*}{ Blue Spruce } & \multirow[t]{4}{*}{1.9} & A & 3.6 & 0.5 & \multirow[t]{16}{*}{ Cypress } & \multirow[t]{4}{*}{1.7} & A & 3.0 & 0.5 \\
\hline & & B & 3.1 & 0.5 & & & B & 3.2 & 0.5 \\
\hline & & $\mathrm{C}$ & 3.1 & 0.4 & & & $\mathrm{C}$ & 3.4 & 0.5 \\
\hline & & D & 3.0 & 0.4 & & & D & 3.0 & 0.4 \\
\hline & \multirow[t]{4}{*}{1.8} & A & 3.8 & 0.5 & & \multirow[t]{4}{*}{1.4} & A & 3.3 & 0.4 \\
\hline & & B & 3.0 & 0.4 & & & B & 2.9 & 0.4 \\
\hline & & $\mathrm{C}$ & 3.1 & 0.4 & & & $\mathrm{C}$ & 3.3 & 0.4 \\
\hline & & D & 3.6 & 0.4 & & & D & 3.8 & 0.4 \\
\hline & \multirow[t]{4}{*}{1.2} & A & 3.2 & 0.4 & & \multirow[t]{4}{*}{1.2} & A & 2.1 & 0.5 \\
\hline & & B & 2.6 & 0.3 & & & B & 3.2 & 0.3 \\
\hline & & $\mathrm{C}$ & 2.5 & 0.3 & & & $\mathrm{C}$ & 3.1 & 0.4 \\
\hline & & D & 2.8 & 0.3 & & & D & 3.3 & 0.4 \\
\hline & \multirow[t]{4}{*}{0.7} & A & 2.5 & 0.4 & & \multirow[t]{4}{*}{0.9} & A & 2.9 & 0.4 \\
\hline & & B & 2.3 & 0.4 & & & B & 3.9 & 0.4 \\
\hline & & $\mathrm{C}$ & 2.2 & 0.4 & & & $\mathrm{C}$ & 3.0 & 0.5 \\
\hline & & D & 2.2 & 0.4 & & & D & 3.8 & 0.5 \\
\hline \multirow[t]{4}{*}{ White Pine } & \multirow[t]{4}{*}{2.8} & A & 4.4 & 0.7 & \multirow[t]{4}{*}{ Fern } & \multirow[t]{4}{*}{0.4} & A & 3.4 & 0.5 \\
\hline & & B & 2.8 & 0.4 & & & B & 3.1 & 0.4 \\
\hline & & $\mathrm{C}$ & 2.1 & 0.4 & & & $\mathrm{C}$ & 3.3 & 0.5 \\
\hline & & $\mathrm{D}$ & 3.6 & 0.5 & & & D & 2.6 & 0.4 \\
\hline \multirow[t]{16}{*}{ Distylium } & \multirow[t]{4}{*}{0.5} & A & 3.2 & 0.4 & \multirow[t]{16}{*}{ Red Holly } & \multirow[t]{4}{*}{2.7} & A & 3.1 & 0.5 \\
\hline & & B & 2.9 & 0.4 & & & B & 2.6 & 0.4 \\
\hline & & $\mathrm{C}$ & 3.1 & 0.4 & & & $\mathrm{C}$ & 2.5 & 0.4 \\
\hline & & D & 3.4 & 0.4 & & & D & 2.7 & 0.4 \\
\hline & \multirow[t]{4}{*}{0.4} & A & 2.7 & 0.3 & & \multirow[t]{4}{*}{2.3} & A & 2.8 & 0.4 \\
\hline & & B & 2.3 & 0.3 & & & B & 2.0 & 0.3 \\
\hline & & $\mathrm{C}$ & 3.1 & 0.4 & & & $\mathrm{C}$ & 2.5 & 0.3 \\
\hline & & D & 2.9 & 0.4 & & & D & 1.8 & 0.3 \\
\hline & \multirow[t]{8}{*}{0.3} & A & 2.0 & 0.3 & & \multirow[t]{4}{*}{2.2} & A & 3.4 & 0.3 \\
\hline & & B & 1.5 & 0.2 & & & B & 2.2 & 0.2 \\
\hline & & $\mathrm{C}$ & 1.7 & 0.3 & & & $\mathrm{C}$ & 2.7 & 0.3 \\
\hline & & D & 2.6 & 0.3 & & & D & 2.5 & 0.3 \\
\hline & & & & & & \multirow[t]{4}{*}{2.1} & A & 2.1 & 0.3 \\
\hline & & & & & & & B & 1.6 & 0.3 \\
\hline & & & & & & & $\mathrm{C}$ & 1.6 & 0.3 \\
\hline & & & & & & & D & 1.7 & 0.3 \\
\hline
\end{tabular}




\section{Comparison Between Vegetation Data and Tube Bank Models}

In comparison to previous work [2-6], the magnitude of the measured drag coefficients in this study is relatively large. As discussed in Section 1, most previous studies have measured the wind resistance of a single plant or tree within a larger wind tunnel while this work considered a relatively homogenous distribution of vegetation within a tunnel. The interpretation of "freestream" velocity, shape factor, cross-sectional area, and so on, are often different in these studies, making it difficult to compare drag coefficients from one study to another. Within the field, there is no single definition of drag coefficient regarding vegetation.

As a way to verify the accuracy of our wind tunnel measurements and the validity of our drag coefficient derivation, we considered a bank of regularly-spaced vertical cylinders within our wind tunnel, using both actual steel rods and empirical results from Idelchik [15]. The pressure loss across two rows of six in-line $2.5 \mathrm{~cm}$ stainless steel cylinders was measured using the experimental setup described in Section 3.3 and shown in Fig. 11. The "resistance coefficient" (termed by Idelchik) for tube banks was calculated from the measurements and the empirical model. Figure 12 shows that the measured resistance coefficient is within experimental uncertainty of Idelchik's empirical model, verifying our experimental approach.

Furthermore, for each of the measured vegetation samples, a comparable configuration of vertical tubes was chosen such that the volume fraction, $\beta$, absorption coefficient, $\kappa$, and characteristic diameter, $D$, match as closely as possible (see Table 3 ). The characteristic diameter was calculated from Eq. (4) using the measured $\beta$ and $\kappa$ values and assuming a cylindrical shape factor $\left(C_{\mathrm{s}}=1 / \pi\right)$. To account for the repeated tube formation for each row, the $\kappa$ value of the tube bank was determined from the distance between rows, $L^{\prime}$, and Eq. (6). Although the length parameter is modified, the control volume definition of the product of the cross-section of the tunnel and depth of the blockage still holds true. According to Idelchik, the expected pressure drop through the tube bank is:

$$
\Delta P=\frac{\rho}{2} \zeta\left(\frac{U}{W}\right)^{2} \quad ; \quad \zeta=A \operatorname{Re}^{-0.27}\left(N_{\mathrm{r}}+1\right) \quad ; \quad \operatorname{Re}=\frac{(U / W) D \rho}{\mu_{\text {air }}}
$$

where $A$ is a geometric parameter determined from the tube bank configuration, $N_{\mathrm{r}}$ is the number of rows of tubes, $W$ is the free-area fraction, $U / W$ is the average velocity of air flowing through the tube array, and Re is the Reynolds number which must be greater than 3000 for the empirical model to apply. Setting the pressure drop, $\Delta P$, in Eq. (10) equal to that in Eq. (7) leads to an equivalent drag coefficient for the tube bank:

$$
C_{\mathrm{d}}=\frac{\zeta / W^{2}}{\kappa L}
$$

Figure 13 compares the drag coefficients from the Gold Rider Leyland Cypress and Bakers Blue Spruce with their tube bank equivalents. While the match is not expected to be perfect given the difference in skin friction, shape, and so on, the drag coefficient of each configuration is comparable. 

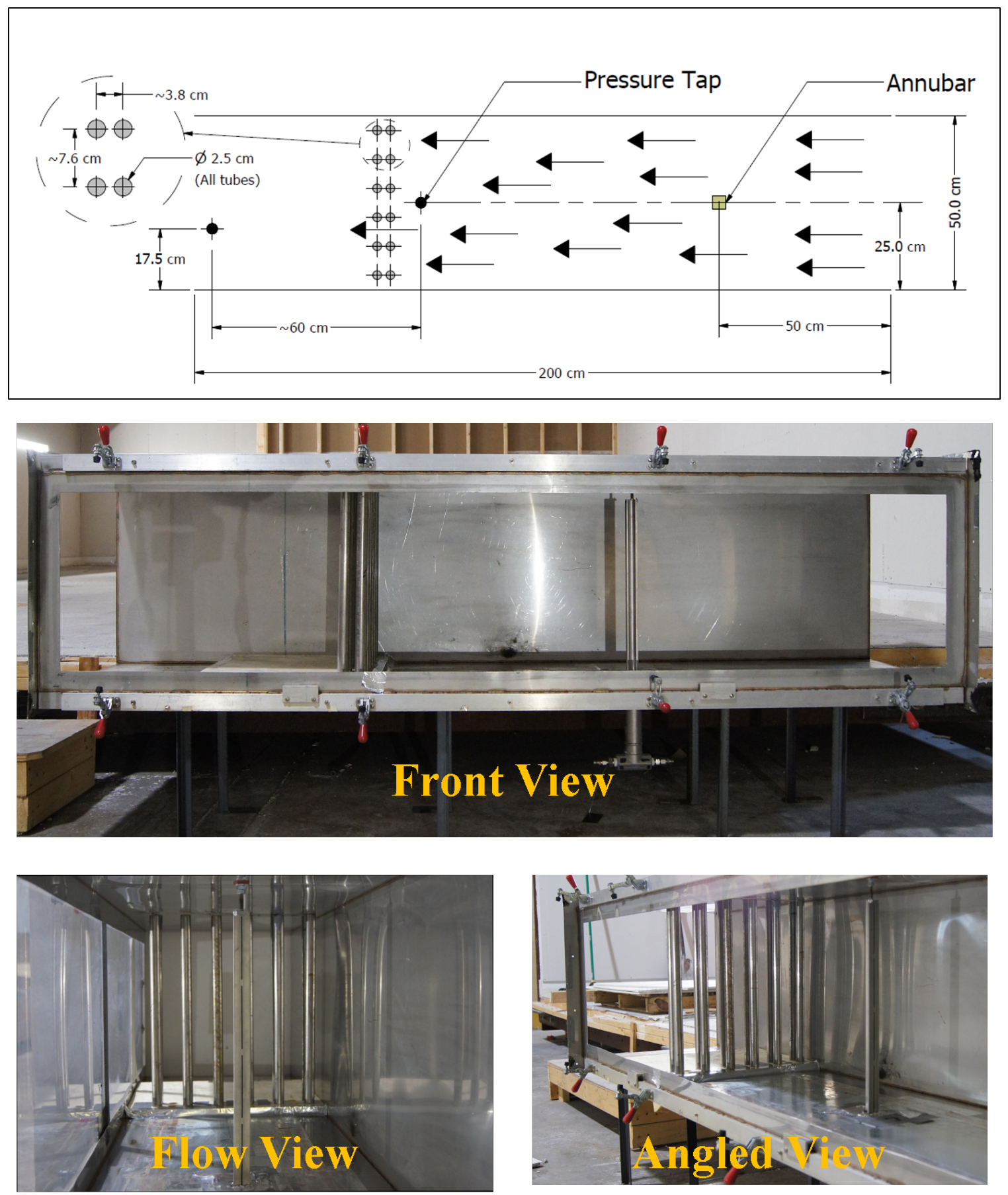

Fig. 11. Tube bank experimental setup with schematic drawing 


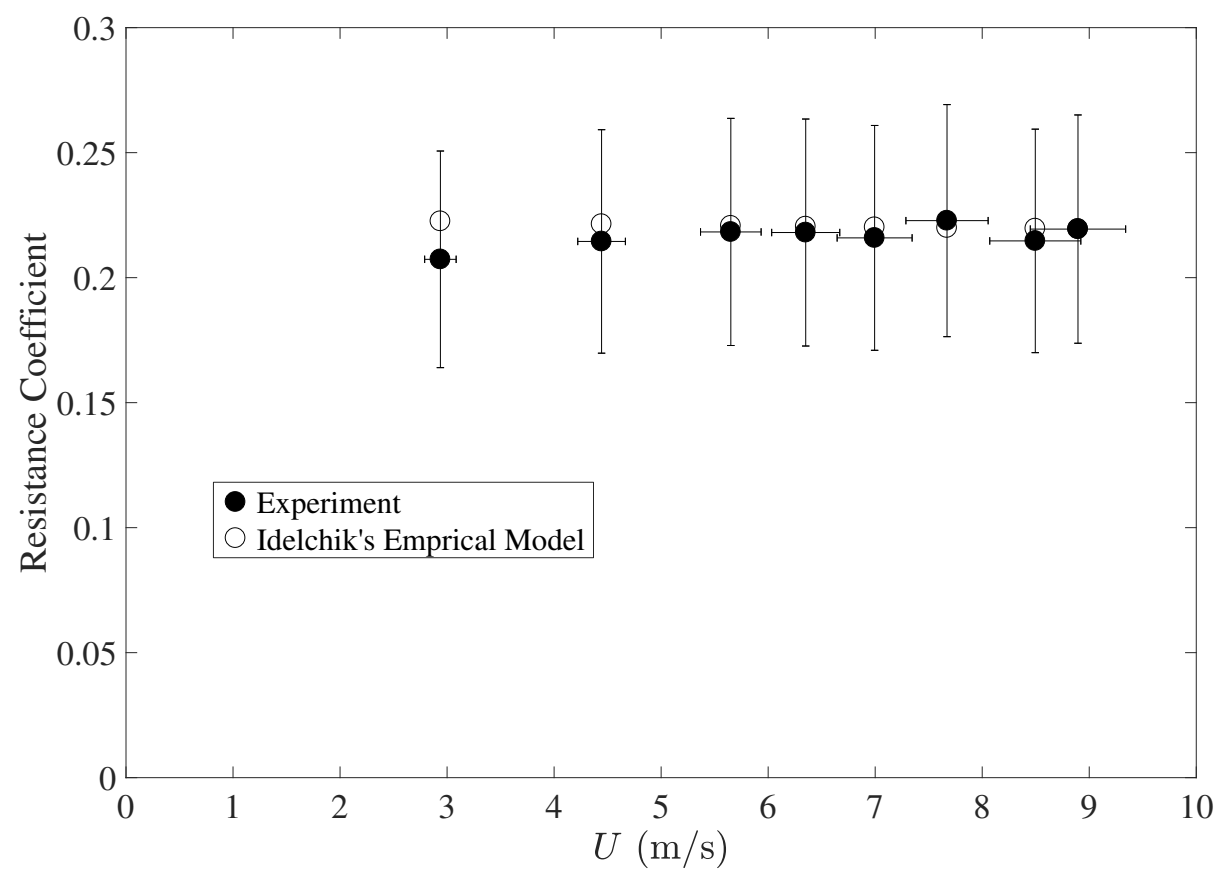

Fig. 12. Comparison between measured and calculated resistance coefficients of tube banks

Table 3. Parameters used in comparing vegetation with a comparable tube bank configuration

\begin{tabular}{|c|c|c|c|c|c|c|c|c|c|c|}
\hline \multirow{2}{*}{ Pos. } & \multicolumn{2}{|c|}{$\beta(\%)$} & \multicolumn{2}{c|}{$\kappa\left(\mathrm{m}^{-1}\right)$} & \multicolumn{2}{c|}{$D(\mathrm{~mm})$} & \multirow{2}{*}{ Rows } & \multirow{2}{*}{ Tubes } & \multirow{2}{*}{$L^{\prime}(\mathrm{cm})$} \\
\cline { 2 - 9 } & Veg. & Tubes & Veg. & Tubes & Veg. & Tubes & & & \\
\hline \hline A & 1.8 & 1.8 & 2.4 & 2.4 & 9.4 & 10.6 & 5 & 10 & 10.0 \\
\hline B & 1.8 & 1.8 & 2.6 & 2.6 & 8.6 & 9.5 & 7 & 9 & 7.1 \\
\hline C & 1.8 & 1.7 & 2.3 & 2.3 & 9.7 & 11.2 & 4 & 11 & 12.5 \\
\hline D & 1.8 & 1.8 & 2.5 & 2.5 & 8.9 & 10.4 & 4 & 13 & 12.5 \\
\hline \multicolumn{10}{|c|}{ Cypress } \\
\hline A & 1.4 & 1.4 & 2.1 & 2.2 & 8.3 & 8.9 & 7 & 8 & 7.1 \\
\hline B & 1.4 & 1.4 & 1.9 & 2.0 & 9.2 & 10.7 & 3 & 13 & 16.7 \\
\hline C & 1.4 & 1.4 & 2.2 & 2.2 & 8.1 & 9.3 & 4 & 13 & 12.5 \\
\hline D & 1.4 & 1.4 & 1.9 & 1.9 & 9.4 & 10.2 & 6 & 7 & 8.3 \\
\hline
\end{tabular}




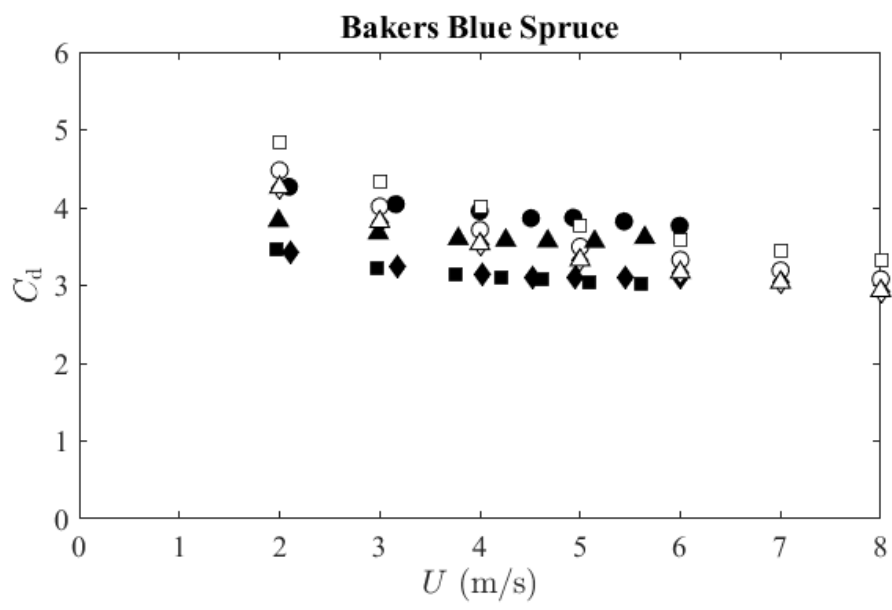

Tube Array Model: Unshaded Vegetation Measurements: Shaded

- Position A

- Position B

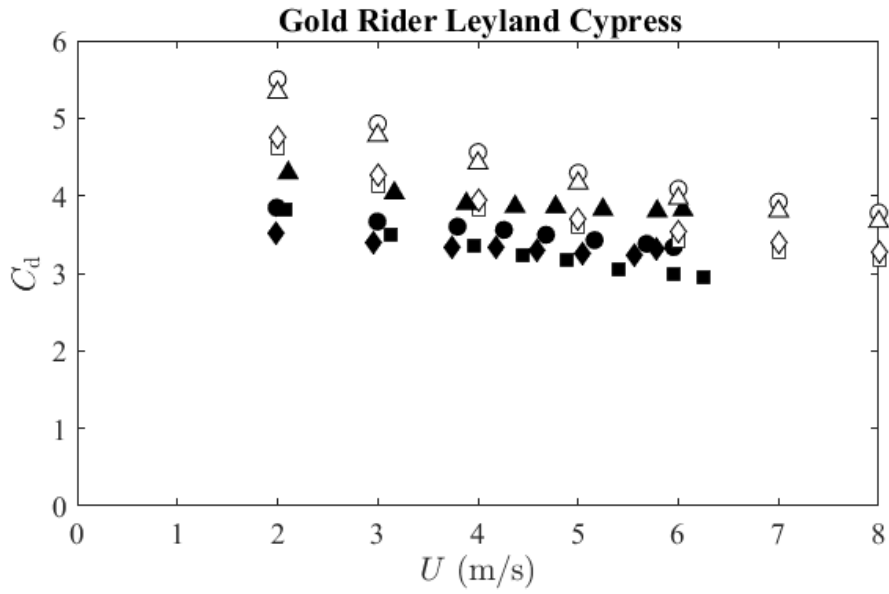

$\diamond$ Position C

$\triangle \boldsymbol{\Delta}$ Position D

Fig. 13. Drag coefficient comparison between vegetation sample configurations [Bakers Blue Spruce $(\beta=1.8 \%)$ and Gold Rider Leyland Cypress $(\beta=1.4 \%)]$ and their corresponding tube bank configuration with respect to velocity. Tube bank configurations were determined using Eq. 10 and by approximating the geometric parameters $(\beta, \kappa$, and $D)$ of the vegetation shown in Table 3 . The tube bank geometric parameters are also shown in Table 3. 


\section{Conclusion}

This report documents a series of experiments implemented to determine the absorption coefficient, pressure loss, and the solid fraction of different types of vegetation sample configurations. The primary objective of this work was to calculate the drag coefficients of bulk vegetation that can be incorporated into CFD models. In addition to establishing drag coefficients of bulk vegetation, notable findings regarding vegetation structure and similarities between drag coefficients of plant species were also discovered from this work. It cannot be concluded, however, that the findings from this work applies to all bulk vegetation, but exclusively to the samples studied in these experiments.

To summarize, the findings of this work are as follows:

1. The calculated absorption coefficient for each sample demonstrated a strong relationship with its corresponding solid fraction.

2. The overall average drag coefficient of the bulk vegetation was found to be 2.8 with an expanded uncertainty of 0.4 . The differences between the average drag coefficients of different plant species as well as the leaf type groups were shown to be significant, while still falling within the overall mean's uncertainty bound, suggesting that the overall average drag coefficient could be used as a constant value in CFD models of various plant types.

3. Compared to previous works, the overall drag coefficient reported in this work is higher than any value reported in past studies [2-6] by a factor of 2 or more. It should be noted that this difference could significantly alter the burning rate behavior of vegetation in CFD calculations. The experimental method of this work was verified using tube banks with well-known drag laws. The experimental setup from this study reproduced these drag coefficients. The difference in drag coefficient from previous work is likely related to fact that in our experimental setup the flow is forced through the vegetation, instead of having a path around the vegetation. Our setup is intentionally designed to mimic computational cells in a CFD calculation, in which the vegetation is treated as a collection of subgrid Lagrangian particles.

\section{Acknowledgments}

The authors would like to thank Matthew Bundy and Artur Chernovksy of the National Fire Research Laboratory at NIST, who assisted in conducting these experiments and in processing the data. 


\section{References}

[1] K. McGrattan, S. Hostikka, R. McDermott, J. Floyd, C. Weinschenk, and K. Overholt. Fire Dynamics Simulator, Technical Reference Guide. National Institute of Standards and Technology, Gaithersburg, Maryland, USA, and VTT Technical Research Centre of Finland, Espoo, Finland, sixth edition, September 2013. Vol. 1: Mathematical Model; Vol. 2: Verification Guide; Vol. 3: Validation Guide; Vol. 4: Software Quality Assurance. 1

[2] J. Cao, Y. Tamura, and A. Yoshida. Wind tunnel study on aerodynamic characteristics of shrubby specimens of three tree species. Urban Forestry and Urban Greening, 11(4):465-476, 2012. 1, 17, 21

[3] J. Jalonen and J. Järvelä. Estimation of drag forces caused by natural woody vegetation of different scales. J. Hydrodynamics, 26(4):608-623, 2014.

[4] G.J. Mayhead. Some Drag Coefficients for British Forest Trees Derived from Wind Tunnel Studies. Agricultural Meterology, 12:123-130, 1973.

[5] J. A. Gillies. Drag coefficient and plant form response to wind speed in three plant species: Burning Bush (Euonymus alatus), Colorado Blue Spruce (Picea pungens glauca.), and Fountain Grass (Pennisetum setaceum). J. Geophysical Research, 107(D24):ACL 10-1-ACL 10-15, 2002.

[6] H. Ishikawa, A. Suguru Amano, and Y. Kenta. Flow around a Living Tree. JSME International Journal, Series B: Fluids and Thermal Engineering, 49(4):1064-1069, 2006. 1, 17, 21

[7] F. Pimont, J.L. Dupuy, R. R. Linn, and S. Dupont. Validation of FIRETEC wind-flows over a canopy and a fuel-break. Int. J. Wildland Fire, 18(7):775-790, Oct. 2009. 1

[8] S. Dupont and Y. Brunet. Edge flow and canopy structure: a large-eddy simulation study. Boundary Layer Meteorology, 126(1):51-71, Jan. 2008. 1

[9] E. Mueller, W. Mell, and A. Simeoni. Large eddy simulation of forest canopy flow for wildland fire modeling. Canadian J. Forest Res., 44(12):1534-1544, Jul. 2014. 2

[10] Emerson Process Management Rosemount Measurement, Chanhassen, Minnesota, USA. Rosemount Annubar® Primary Flow Element Flow Test Data Book, July 2009. 6,25

[11] D Lane and N Salkin. Tukey's honestly significant difference (hsd). N. Salkind der.), Encyclopedia of Research Design içinde, Thousand Oaks, CA: SAGE Publications, 1:1566-1571, 2010. 14

[12] B. Toman and A. Possolo. Laboratory effects models for interlaboratory comparisons. Accreditation and Quality Assurance, 14(10):553-563, October 2009. 15

[13] A. Gelman, J. Carlin, H. Stern, and D. Rubin. Bayesian Data Analysis, 2nd Edition. Chapman and Hall/CRC, 2013. 15

[14] David Lunn, David Spiegelhalter, Andrew Thomas, and Nicky Best. The bugs project: Evolution, critique and future directions. Statistics in medicine, 28(25):3049-3067, October 2009. 15 
[15] I.E. Idelchik. Handbook of Hydraulic Resistance, 3rd Edition. CRC Press, Inc., 1994. 17 


\section{A. Uncertainty Analysis of the Drag Coefficient}

The drag coefficient was calculated using a combination of Eqs. (6) and (7):

$$
C_{\mathrm{d}}=\frac{-2 \Delta P}{\rho U^{2} \ln W}
$$

where $\Delta P$ is the pressure drop across the vegetation sample, measured with a pressure transducer, $\rho$ is the air density, obtained via pressure, temperature, and relative humidity measurements and the ideal gas law, $U$ is the average velocity of air through the wind tunnel, measured using an Annubar, and $W$ is the free area coefficient of the vegetation, measured using photography and image analysis. The uncertainty of the measured drag coefficient was estimated using the law of propagation of uncertainty after determining the drag coefficient:

$$
u_{\mathrm{c}}=\sqrt{\left(\frac{\partial C_{\mathrm{d}}}{\partial \Delta P} u_{\Delta P}\right)^{2}+\left(\frac{\partial C_{\mathrm{d}}}{\partial \rho} u_{\rho}\right)^{2}+\left(\frac{\partial C_{\mathrm{d}}}{\partial U} u_{U}\right)^{2}+\left(\frac{\partial C_{\mathrm{d}}}{\partial W} u_{W}\right)^{2}}
$$

A coverage factor of 2 is applied to the combined uncertainty to produce a $95 \%$ confidence interval.

\section{A.1 Pressure}

Two pressure transducers were used in this study. Transducer 1 measured the differential pressure across the vegetation while Transducer 2 measured the differential pressure across the Annubar. The Type A evaluation of standard uncertainty of the pressure difference, $\Delta P$, was taken as the standard deviation, $s_{\Delta P}$, of the measurements sampled at $90 \mathrm{~Hz}$ for $30 \mathrm{~s}$. The Type B evaluation of standard uncertainty was determined from the calibration error sources of the pressure transducers and was found to be $u_{\text {cal }}=1.4 \mathrm{~Pa}$ and $u_{\text {cal }}=1.5 \mathrm{~Pa}$ for Transducers 1 and 2, respectively. The combined uncertainty was found via quadrature:

$$
u_{\Delta P}=\sqrt{u_{\mathrm{cal}}^{2}+s_{\Delta P}^{2}}
$$

\section{A.2 Air Density}

The density of air was determined from the absolute pressure, temperature, and relative humidity readings obtained simultaneously with the wind tunnel measurements:

$$
\rho=\frac{P}{R T}
$$

where $T$ is the measured air temperature, $P$ is the absolute pressure, and $R$ is the specific gas constants for air $(287 \mathrm{~J} /(\mathrm{kg} \cdot \mathrm{K})$. The Type A evaluation of uncertainty of air density was determined from the standard uncertainty of the absolute pressure, $s_{P}$, and temperature, $s_{T}$, 
readings of the testing facility. The Type $\mathrm{B}$ evaluation of air density was determined from the error sources in the instrauments, $u_{\text {inst. }}$, used to measure the absolute pressure $(1 \%$ accuracy of the pressure gauge) and temperature $\left(1.5^{\circ} \mathrm{C}\right)$ of air in the testing facility. The combined uncertainty of the pressure and temperature was found via quadrature:

$$
\begin{aligned}
& u_{P}=\sqrt{u_{\text {inst. }}^{2}+s_{P}^{2}} \\
& u_{T}=\sqrt{u_{\text {inst. }}^{2}+s_{T}^{2}}
\end{aligned}
$$

The standard uncertainty of the air density was determined through the law propagation of uncertainties:

$$
u_{\rho}=\sqrt{\left(\frac{\partial \rho}{\partial P} u_{P}\right)^{2}+\left(\frac{\partial \rho}{\partial T} u_{T}\right)^{2}}
$$

\section{A.3 Velocity}

The average air velocity through the wind tunnel, $U$, was measured using an Annubar and calculated using the following formula:

$$
U=K \sqrt{\frac{2 \Delta P}{\rho}}
$$

where $K$ is a flow coefficient and $\Delta P$ is the pressure difference measured by Transducer 2 discussed above. The Type $\mathrm{B}$ evaluation of standard uncertainty of the flow coefficient was assumed to be $5 \%$ of the reading ${ }^{6}$. The standard uncertainty of the velocity was determined through the law of propagation of uncertainties:

$$
u_{U}=\sqrt{\left(\frac{\partial U}{\partial \Delta P} u_{\Delta P}\right)^{2}+\left(\frac{\partial U}{\partial \rho} u_{\rho}\right)^{2}+\left(\frac{\partial U}{\partial K} u_{K}\right)^{2}}
$$

\section{A.4 Free-Area Coefficient}

The uncertainty of the free-area coefficient was determined by measuring the projected areas of objects with known dimensions using the same photographic method described in Section 3.2. The standard deviation of the difference between the measured and true freearea coefficients was found to be $u_{W}=0.01$, which was treated as a Type B evaluation of standard uncertainty for all free-area coefficients of the vegetation samples.

\footnotetext{
${ }^{6} \mathrm{~A} 485$ Calibrated Annubar is reported to have an accuracy of $0.5 \%$ in circular ducts as reported by [10]. However, since an Annubar was used in a square duct in these experiments, the uncertainty of the flow coefficient was adjusted to $5 \%$ after contacting the manufacturer.
} 


\section{B. Uncertainty Analysis of the Absorption Coefficient}

The absorption coefficient was calculated by adjusting Eq. (6)

$$
\kappa=\frac{-\ln W}{L}
$$

where $W$ is the relative fraction of light passing through a distance of $L$, also known as the free-area coefficient. The uncertainty of the free-area coefficient, $W$, is discussed in Appendix A.4. Vegetation samples trimmed using the guiding frame were found to have a standard deviation of for their respective cubic lengths of $5.0 \mathrm{~mm}$ which was treated as a Type B evaluation of standard uncertainty. The standard uncertainty of the absorption coefficient was determined through the law of propagation of uncertainties:

$$
u_{\kappa}=\sqrt{\left(\frac{\partial \kappa}{\partial W} u_{W}\right)^{2}+\left(\frac{\partial \kappa}{\partial L} u_{L}\right)^{2}}
$$




\section{Uncertainty Analysis of the Solid Fraction of Vegetation}

The solid fraction of vegetation was calculated using the following formula

$$
\beta=\frac{V_{\text {veg. }}-V_{\text {abs.water }}}{V_{\text {total }}}
$$

where $V_{\text {veg. }}, V_{\text {abs.water }}$, and $V_{\text {total }}$ are the volumes of the vegetation, absorbed water, and total occupancy $\left(0.125 \mathrm{~m}^{3}\right)$, respectively. The standard uncertainty of the solid fraction was determined through the law of propagation of uncertainties:

$$
u_{\beta}=\sqrt{\left(\frac{\partial \beta}{\partial V_{\text {veg. }}} u_{V_{\text {veg. }}}\right)^{2}+\left(\frac{\partial \beta}{\partial V_{\text {abs.water }}} u_{V_{\text {abs.water }}}\right)^{2}+\left(\frac{\partial \beta}{\partial V_{\text {total }}} u_{V_{\text {total }}}\right)^{2}}
$$

\section{C.1 Volume of Vegetation}

The combined standard uncertainty of the measured solid sample volume combines, via quadrature, the Type A standard uncertainty, taken as the standard deviation of the repeated measurements, and the Type B standard uncertainty, taken as the standard deviation of the assumed uniform distribution that characterizes the uncertainty in the reading of the graduated cylinder, $5 / \sqrt{12} \mathrm{~mL}$, where the cylinder has $5 \mathrm{~mL}$ grading divisions.

\section{C.2 Volume of Water Absorbed}

The volume of water absorbed in the vegetation was determined from the difference in mass of the vegetation before and after water discplacement tests divided by the density of water at room temperature $(1.0 \mathrm{~g} / \mathrm{mL})$. The mass of the vegetation was measured using a Mettler Toledo load cell. The uncertainty of the measured mass was assumed to be $5 \mathrm{~g}$ and was treated as a Type B standard uncertainty for all mass measurments.

\section{C.3 Volume of Total Occupancy}

The uncertainty of the volume of total occupancy was determined from the uncertianty of the cubic length described in Appendix B. 